\title{
Application of extracorporeal membrane oxygenation in patients with severe acute respiratory distress syndrome induced by avian influenza A (H7N9) viral pneumonia: national data from the Chinese multicentre collaboration
}

Linna Huang ${ }^{1+}$, Wei Zhang ${ }^{2+}$, Yi Yang ${ }^{3 \dagger}$, Wenjuan Wu ${ }^{4+}$, Weihua Lu $^{5+}$, Han Xue ${ }^{6}$, Hongsheng Zhao ${ }^{7}$, Yunfu Wu ${ }^{8}$, Jia Shang ${ }^{9}$, Lihua Cai ${ }^{10}$, Long Liu ${ }^{11}$, Donglin Liu', Yeming Wang ${ }^{1}$, Bin Cao ${ }^{1 *}$, Qingyuan Zhan ${ }^{1 *}$ and Chen Wang ${ }^{1}$

\begin{abstract}
Background: Evidence concerning the efficacy and safety of extracorporeal membrane oxygenation (ECMO) in patients with influenza A (H7N9) has been was limited to case reports. Our study is aimed to investigate the current application, efficacy and safety of ECMO in for severe H7N9 pneumonia-associated acute respiratory distress syndrome (ARDS) in the Chinese population.

Methods: A multicentre retrospective cohort study was conducted at 20 hospitals that admitted patients with avian influenza A (H7N9) viral pneumonia patients' admission from 9 provinces in China between October 1, 2016, and March 1, 2017. Data from the National Health and Family Planning Commission of China, including general conditions, outcomes and ECMO management, were analysed. Then, successfully weaned and unsuccessfully weaned groups were compared.
\end{abstract}

Results: A total of 35 patients, aged $57 \pm 1$ years, were analysed; $65.7 \%$ of patients were male with $63 \%$ mortality. All patients underwent invasive positive pressure ventilation (IPPV), and rescue ventilation strategies were implemented for 23 cases (65.7\%) with an average IPPV duration of $5 \pm 1 \mathrm{~d}, \mathrm{PaO}_{2} / \mathrm{FiO}_{2}$ of $78 \pm 23 \mathrm{mmHg}$, tidal volume (VT) of $439 \pm 61 \mathrm{ml}$ and plateau pressure $\left(\mathrm{P}_{\text {plat }}\right)$ of $29 \pm 8 \mathrm{cmH}_{2} \mathrm{O}$ pre-ECMO. After $48 \mathrm{~h}$ on $\mathrm{ECMO}, \mathrm{PaO}_{2}$ improved from $56 \pm 21 \mathrm{mmHg}$ to $90 \pm 24 \mathrm{mmHg}$ and $\mathrm{PaCO}_{2}$ declined from $52 \pm 24 \mathrm{mmHg}$ to $38 \pm 24 \mathrm{mmHg}$. Haemorrhage, ventilator-associated pneumonia (VAP) and barotrauma occurred in $45.7 \%, 60 \%$ and $8.6 \%$ of patients, respectively. Compared with successfully weaned patients $(n=14)$, the 21 unsuccessfully weaned patients had a longer duration of IPPV pre-ECMO ( $6 \pm 4$ d vs. $2 \pm 1 \mathrm{~d}, P<0.01)$ as well as a higher $\mathrm{P}_{\text {plat }}\left(25 \pm 5 \mathrm{cmH}_{2} \mathrm{O}\right.$ vs. $\left.21 \pm 3 \mathrm{cmH}_{2} \mathrm{O}, P<0.05\right)$ and VT $(343 \pm 96 \mathrm{ml}$ vs. $246 \pm 93 \mathrm{ml}, \mathrm{P}<0.05)$ after $48 \mathrm{~h}$ on ECMO support. Furthermore, the unsuccessfully weaned group had a higher mortality $(100 \%$ vs. $7.1 \%, P<0.01)$ with more haemorrhage $(77.3 \%$ vs. $28.6 \%, P<0.01)$.

(Continued on next page)

\footnotetext{
*Correspondence: caobin1999@gmail.com; drzhanqy@163.com

†'Equal contributors

'Department of Pulmonary and Critical Care Medicine, Centre for Respiratory

Diseases, China-Japan Friendship Hospital, No. 2 Yinghua East Road,

Chaoyang District, Beijing 100029, People's Republic of China

Full list of author information is available at the end of the article
} 
(Continued from previous page)

Conclusions: ECMO is effective at improving oxygenation and ventilation of patients with avian influenza A (H7N9) induced severe ARDS. Early initiation of ECMO with appropriate IPPV settings and anticoagulation strategies are necessary to reduce complications.

Keywords: Extracorporeal membrane oxygenation (ECMO), Avian influenza A (H7N9), Acute respiratory distress syndrome (ARDS), Complications, Mortality

\section{Background}

Avian influenza A (H7N9) viral pneumonia can manifest with varying degrees of dyspnea and is associated with a mortality of $\sim 30 \%$ [1]. In particular, $97 \%$ of patients develop rapidly progressive pneumonia and $71 \%$ progress to acute respiratory distress syndrome (ARDS). The mortality of severe ARDS is as high as $62 \%$ [2].

Timely and effective respiratory support is particularly important to treat severe ARDS caused by avian influenza A (H7N9) pneumonia. However, severe ARDS induced by avian influenza A (H7N9) pneumonia might manifest as refractory hypoxaemia even with appropriate invasive positive pressure ventilation (IPPV) support. Extracorporeal membrane oxygenation (ECMO) is the ultimate respiratory support method and directly improves the oxygenation and ventilation of patients as well as enables implementation of the "lung protective ventilation strategy" [3]. ECMO was the breakthrough treatment for the severe avian influenza A (H1N1) outbreak of 2009 and reduced mortality from this outbreak [4-6]. Therefore, we believe that ECMO could also be effective for other types of severe viral pneumonia.

Existing studies of ECMO treatment for avian influenza A (H7N9) pneumonia are primarily limited to case reports [7-9], and no study has systematically reviewed the efficacy or safety of ECMO to treat such diseases. Therefore, it is particularly important to understand the current application of ECMO for avian influenza A (H7N9) pneumonia-induced severe ARDS, investigate the application timing and management strategies of $\mathrm{ECMO}$, and explore the possible reasons for treatment failure. Based on the current study, we expect to standardize the management of ECMO and provide a description of our experiences using ECMO to treat patients with avian influenza A (H7N9) pneumoniainduced severe ARDS.

\section{Methods}

\section{Study population and data collection}

Patients who had laboratory-confirmed avian influenza A (H7N9) virus-induced pneumonia were included in this study. Patients were admitted to 20 hospitals in 9 provinces of China between October 1, 2016, and March 1, 2017, and were reported to the National Health and Family Planning Commission of China.
We included patients aged $>14$ ys who were supported by ECMO. Patients who were lacking key detailed records of parameters during ECMO, such as ventilator or laboratory findings, were excluded.

The included patients were divided into 2 groups, namely, the "successfully weaned group" and "unsuccessfully weaned group". The former refers to a group of patients whose condition improved and were weaned from ECMO for at least $48 \mathrm{~h}$; the "unsuccessfully weaned group" refers to those who died or voluntarily discontinued treatment due to lack of improvement during ECMO support.

\section{General conditions}

The general conditions included age, gender, pregnancy status, underlying disease, time from onset to antiviral drug administration, vasoactive drug administration pre-ECMO, duration of IPPV pre-ECMO, whether rescue ventilation strategies (including lung recruitment maneuvre, prone-position ventilation, and high-frequency oscillation ventilation) were implemented pre-ECMO, disease severity score, total duration of ECMO and IPPV.

\section{Conditions during ECMO}

We collected the ECMO blood flow at 24, 48, 72, and $96 \mathrm{~h}$ on ECMO. Improvement in circulatory and respiratory physiological indicators were considered, as well as IPPV parameters at $6 \mathrm{~h}$ pre-ECMO and 24, 48, and $72 \mathrm{~h}$ on ECMO. Furthermore, anticoagulation indicators during ECMO, including the types of anticoagulant drugs and methods of use; the maximum and minimum values of the activated coagulation time (ACT) and activated partial thromboplastin time (APTT); and the differences between the maximum and minimum ACT and APTT at 24,48 , and $72 \mathrm{~h}$ on ECMO were recorded. Finally, data regarding complications during ECMO therapy, including ECMO and IPPV-related complications and nosocomial infections, were collected.

\section{Study definitions and design Outcomes}

The primary outcome was in-hospital mortality. The secondary outcomes were the length of stay in the intensive care unit (ICU) and total length of hospitalization. 


\section{Definition of avian influenza A (H7N9) virus infection}

Three methods were used for a laboratory diagnosis, namely, the real-time reverse transcription-polymerase chain reaction (RT-PCR), viral isolation, and serological testing for the avian influenza A (H7N9) virus using a modified haemagglutinin inhibition assay [10-12].

\section{Definition of acute respiratory syndrome (ARDS)}

We defined ARDS according to the Berlin definition in $2012[13,14]$.

\section{Definitions of pneumonia and severe pneumonia}

Pneumonia was diagnosed as an acute illness with fever, cough, or dyspnea/tachypnea, and at least one new focal chest sign that was supported by a finding of lung shadowing on a chest radiograph and without other noninfectious causes.

The primary criteria for severe pneumonia were as follows: $<1>$ need for tracheal intubation and mechanical ventilation (MV) and $<2>$ need for vasoactive drugs after the active fluid resuscitation due to septic shock. The secondary criteria were as follows: $<1>$ respiratory rate $\geq 30$ times/ min; $<2>\mathrm{PaO}_{2} / \mathrm{FiO}_{2} \leq 250 \mathrm{mmHg} ;<3>$ multiple lobe infiltration; $<4>$ disturbances of consciousness, disorientation, or both; $<5>$ blood urea nitrogen $\geq 7.14 \mathrm{mmol} / \mathrm{L}$; and $<6>$ systolic blood pressure $\leq 90 \mathrm{mmHg}$ that required active fluid resuscitation. Patients who met one primary criterion or at least three secondary criteria were diagnosed as having severe pneumonia [15].

\section{Definitions of ventilator-associated pneumonia (VAP)}

The criteria for the diagnosis of VAP are in accordance with the European Centre for Disease Prevention and Control [16] and included the following: $<1>$ two or more sequential chest $\mathrm{x}$-rays or $\mathrm{CT}$ scans with a suggestive image of pneumonia for patients with underlying cardiac or pulmonary disease, or one definitive chest $\mathrm{x}$-ray or CT scan in patients without underlying cardiac or pulmonary disease; $<2>$ a fever greater than $38{ }^{\circ} \mathrm{C}$ and/ or leukocytosis greater than or equal to $12,000 \mathrm{WBC} /$ $\mathrm{mm}^{3}$ or leukopenia less than or equal to $4000 \mathrm{WBC} /$ $\mathrm{mm}^{3}$; and $<3>$ at least one of the following: $<\mathrm{a}>$ new onset of purulent sputum or change in the characteristics of the sputum; $<\mathrm{b}>$ cough, dyspnea, or tachycardia; $<\mathrm{c}>$ auscultatory findings, such as rales, bronchial breath sounds, ronchi, or wheezing; or $<\mathrm{d}>$ worsening gas exchange (e.g., oxygen desaturation or increased oxygen requirements or increased ventilation demand).

For all included patients, we first described the general conditions, ECMO model and parameters, IPPV parameters, the changes in circulation and respiratory physiological indicators from pre-ECMO to on ECMO status, anticoagulation on ECMO, and complications during ECMO therapy in all included patients. Then, we compared patients who were successfully or unsuccessfully weaned from ECMO with regard to above items.

\section{Statistical analysis}

All of the analyses were performed using SPSS 17.0 software. Normally distributed continuous variables are expressed as the means \pm SD and were compared using the t-test or chi-square test. Non-normally distributed continuous variables are expressed as medians and quartiles and were compared using the Wilcoxon rank-sum test. Categorical variables were compared using the $x^{2}$ test. $P$-values $<0.05$ were considered significant.

\section{Results}

A total of 473 patients were diagnosed with avian influenza A (H7N9) virus-related pneumonia. Patients were admitted to 20 hospitals in 9 provinces of China between October 1, 2016, and March 1, 2017, and were reported to the National Health and Family Planning Commission of China. The medical records of 216 patients were available, and 36 patients were reported to be supported by ECMO. One of the 36 patients lacked IPPV and ECMO parameters pre-ECMO and on ECMO and was eliminated as a participant; therefore, 35 patients were ultimately selected (Fig. 1).

\section{General conditions and outcomes}

Data from 35 patients (65.7\% males), with an average age of $57 \pm 1$ years, were analysed. There was no patient under the age of 16. A total of 22 patients had underlying diseases, 8 patients were treated with steroids and immunosuppressive agents within 1 month of admission to the hospital, and 1 patient was pregnant. The Sequential Organ Failure Assessment (SOFA) score was $9 \pm 3$ points, and the Murray score was $3.6 \pm 0.4$ points. The time from onset to antiviral drug administration was approximately $9 \pm 5 \mathrm{~d}$, and the time from onset to ECMO support was approximately $10 \pm 3 \mathrm{~d}$. High-dose vasoactive drugs [17] were needed to maintain blood pressure in 20 patients $(57.1 \%)$. The duration of IPPV preECMO was approximately $5 \pm 1$ d. Rescue ventilation strategies, including the recruitment manoeuvre (RM), prone-position ventilation (PP) and high frequency oscillatory ventilation (HFOV), were needed for 23 patients (65.7\%) pre-ECMO. The total durations of IPPV and ECMO were approximately $20 \pm 8 \mathrm{~d}$ and $8 \mathrm{~d}$ (5-13 d), respectively. Of the 35 patients, 14 (40\%) were successfully weaned from ECMO, and the other 21 patients died due to an uncontrolled haemorrhage (5 patients), septic shock (6 patients due to progressive lung infection, 3 patients due to bloodstream infection), heart failure ( 2 patients) and discontinuation of treatment because of no improvement (5 patients). One of 14 patients showed an aggregated lung infection after weaning 


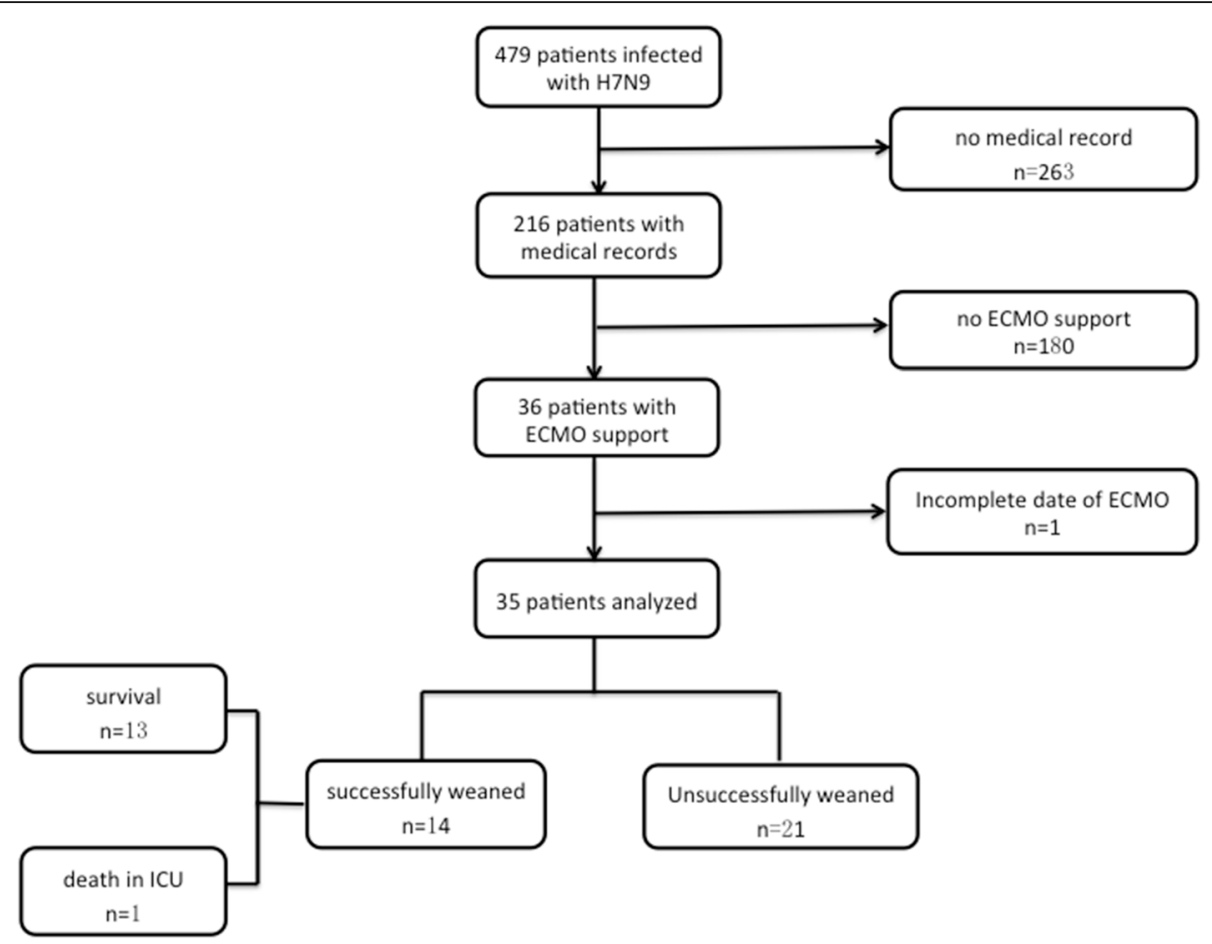

Fig. 1 Flowchart. A flowchart illustrating the enrolment of patients with avian influenza A (H7N9) virus-induced pneumonia who were reported to the National Health and Family Planning Commission of China; patients were admitted to 20 hospitals in 9 provinces of China between October 1 , 2016, and March 1, 2017

and eventually died due to septic shock. The inhospital mortality was $63 \%$. The length of ICU stay was $27 \pm 14 \mathrm{~d}$, and the total length of hospitalization was $31 \pm 14 \mathrm{~d}$ (Table 1$)$.

\section{Conditions during ECMO}

ECMO mode and information concerning the equipment Of the 35 patients, 33 were treated using the veno-venous ECMO (V-V ECMO) model. A total of 2 patients with severe cardiac insufficiency and cardiogenic shock were treated using the venous-arterial ECMO (V-A ECMO) model. The ECMO equipment was mainly provided by MAQUET (Shanghai) Medical Equipment Co., Ltd. and SORIN (Shanghai) Medical Equipment Co., Ltd. The pump from SORIN was the Stockert Centrifugal Pump System (SCP/SCPC), and the oxygenator was the D905 EOS ECMO. The pump from MAQUET was the ROTAFLOW, and the oxygenator was the QUADROX PLS.

\section{ECMO management}

Changes in IPPV parameters and physiological indicators in patients on ECMO The ventilator parameters, including $\mathrm{FiO}_{2}$, positive end-expiratory pressure (PEEP), $\mathrm{P}_{\text {plat }}$, and VT, were significantly decreased in patients on ECMO. The vital signs, which included the heart rate, respiratory rate, and $\mathrm{SpO}_{2}$, and the arterial blood gas analysis (ABG), which included the $\mathrm{pH}$, $\mathrm{PaCO}_{2}$, and $\mathrm{PaO}_{2}$ levels, were improved in patients after ECMO support (Table 2).

Monitoring of anticoagulation All 35 patients received a continuous infusion of unfractionated heparin for anticoagulation. However, heparin was discontinued for 2 patients with cerebral haemorrhage and 3 with active gastrointestinal haemorrhage. The ACT was $144 \pm 61$ to $220 \pm 66 \mathrm{~s}$ at $24 \mathrm{~h}, 16 \pm 37$ to $234 \pm 37 \mathrm{~s}$ at $48 \mathrm{~h}$, and 147 \pm 26 to $221 \pm 40 \mathrm{~s}$ at $72 \mathrm{~h}$ on ECMO. The APTT was 58 \pm 23 to $84 \pm 28 \mathrm{~s}$ and $53 \pm 15$ to $75 \pm 23 \mathrm{~s}$ at 48 and $72 \mathrm{~h}$ on ECMO, respectively.

Complications during ECMO therapy In this study, the rates of gastrointestinal haemorrhage, cerebral haemorrhage, brain death, renal insufficiency, disseminated intravascular coagulation (DIC), hyperglycaemia, and ECMO oxygenator thrombosis were higher compared to the relevant data from the ECLS Registry Report $[18,19]$. New cases of VAP developed in 21 patients during ECMO, with an incidence rate of $60 \%$. New cases of barotrauma occurred in 3 patients, accounting for $8.6 \%$ of cases. In addition, 6 patients had a urinary infection, with an incidence rate of $17.1 \%$, and 10 patients had a catheter-related blood stream infection (CRBSI), with an incidence rate of $28.6 \%$ (Table 3 ). 
Table 1 General conditions and outcomes of patients with ECMO therapy

\begin{tabular}{|c|c|c|c|c|}
\hline Variable & Total $(n=35)$ & $\begin{array}{l}\text { Successfully weaned } \\
\text { group }(n=14)\end{array}$ & $\begin{array}{l}\text { Unsuccessfully weaned } \\
\text { group }(n=21)\end{array}$ & $P$ value \\
\hline \multicolumn{5}{|l|}{ Gender, number (\%) } \\
\hline Male & $23(65.7)$ & $9(64.3)$ & $14(66.7)$ & 1.00 \\
\hline Age, years, mean $\pm S D$ & $57 \pm 1$ & $51 \pm 10$ & $60 \pm 12$ & $0.02^{*}$ \\
\hline \multicolumn{5}{|l|}{ Underlying Diseases, number (\%) } \\
\hline Hypertension & 19(54.3) & $7(50)$ & $12(57.1)$ & 0.74 \\
\hline Diabetes & 13(37.1) & $1(7.1)$ & 12(57.1) & $<0.01^{*}$ \\
\hline Cerebrovascular disease & $5(14.3)$ & $3(21.4)$ & $2(9.5)$ & 0.37 \\
\hline History of steroid and immunosuppressant within 1 month & $8(22.9)$ & $4(28.6)$ & $4(19.0)$ & 0.69 \\
\hline Pregnancy, number (\%) & $1(2.9)$ & $0(0.0)$ & $1(47.6)$ & 1.00 \\
\hline Onset to NAI & $9 \pm 5$ & $7 \pm 3$ & $11 \pm 6$ & $0.04^{*}$ \\
\hline Onset to ECMO & $10 \pm 3$ & $10 \pm 3$ & $10 \pm 3$ & 0.97 \\
\hline \multicolumn{5}{|l|}{ Organ support pre-ECMO } \\
\hline High-dose vasoactive drugs ${ }^{\mathrm{a}}$, number (\%) & 20(57.1) & $6(42.9)$ & 14(63.6) & 0.31 \\
\hline Rescue ventilation strategies ${ }^{\mathrm{b}}$, number (\%) & $23(65.7)$ & $6(43.9)$ & 17(81.0) & $0.03^{*}$ \\
\hline Duration of IPPV, days, mean \pm SD & $5 \pm 1$ & $2 \pm 1$ & $6 \pm 4$ & $<0.01^{*}$ \\
\hline SOFA Score & $9 \pm 3$ & $7 \pm 2$ & $10 \pm 4$ & $0.02^{*}$ \\
\hline Murray Score & $3.6 \pm 0.4$ & $3.6 \pm 0.5$ & $3.6 \pm 0.4$ & 0.95 \\
\hline $\mathrm{PaO}_{2} / \mathrm{FiO}_{2}$ pre-ECMO, $\mathrm{mmHg}$, mean $\pm \mathrm{SD}$ & $78 \pm 23$ & $89 \pm 24$ & $71 \pm 20$ & $0.04^{*}$ \\
\hline Duration of ECMO, days, median (IQR) & $8(5-13)$ & 10(7-13) & $7(3-16)$ & 0.48 \\
\hline Total Duration of IPPV, days, mean \pm SD & $20 \pm 8$ & $23 \pm 13$ & $18 \pm 15$ & 0.36 \\
\hline \multicolumn{5}{|l|}{ Clinical outcomes } \\
\hline Mortality, number (\%) & $22(63)$ & $1(7.1)$ & $21(100)$ & $<0.01^{*}$ \\
\hline Length of stay in ICU, days, mean \pm SD & $27 \pm 14$ & $33 \pm 12$ & $24 \pm 14$ & 0.081 \\
\hline Length of hospitalization, days, mean \pm SD & $31 \pm 14$ & $39 \pm 10$ & $27 \pm 14$ & $0.010^{*}$ \\
\hline
\end{tabular}

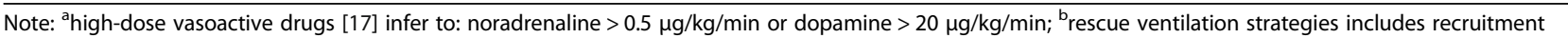
maneuver (RM), prone position ventilation (PP) and high frequency oscillatory ventilation (HFOV)

$N A I$ neuraminidase inhibitors, IPPV invasive positive pressure ventilation, ECMO extracorporeal membrane oxygenation, SOFA score sequential organ failure score, ICU intensive care unit

We made comparison between successfully weaned and unsuccessfully weaned group using t-test, $\mathrm{x}^{2}$ test or Wilcoxon rank-sum test, and $P$ values $<0.05$ were considered significant, marked as *

\section{Comparison between the patients successfully and unsuccessfully weaned from ECMO}

Group 1 contained 14 patients who were successfully weaned from ECMO, and group 2 included 21 patients who were unsuccessfully weaned from ECMO.

Compared with patients successfully weaned from ECMO, the unsuccessfully weaned group had a higher mortality ( $100 \%$ vs. $7.1 \%$, respectively, $P<0.01)$, and was older $(60 \pm 12$ years vs. $51 \pm 10$ years, respectively, $P=$ $0.02)$, and more likely to have diabetes mellitus $(57.1 \%$ vs. $7.1 \%$, respectively, $P<0.01$ ), had more frequent severe conditions (SOFA: $10 \pm 4$ points vs. $7 \pm 2$ points, respectively, $\mathrm{P}<0.01)$ pre-ECMO. Meanwhile, they had a longer duration of IPPV $(6 \pm 4$ d vs. $2 \pm 1$ d, respectively, $P<$ $0.01)$, had lower $\mathrm{PaO}_{2} / \mathrm{FiO}_{2}$ levels $(71.4 \pm 20.0 \mathrm{mmHg}$ vs. $89.3 \pm 24.2 \mathrm{mmHg}$, respectively, $P<0.05)$, and higher rate of rescue ventilation strategies ( $81 \%$ vs. $43.9 \%$, respectively, $P<0.05)$ before ECMO support. No significant differences were found in the total duration of IPPV, total duration of ECMO, length of ICU stay and length of hospitalization between the two groups (Table 1).

\section{Blood flow in patients on ECMO}

ECMO blood flow did not significantly differ between the two groups during the initiation of ECMO support. However, in the successfully weaned group vs. the unsuccessfully weaned group, a significant decrease in blood flow correlated with an increase in the duration of support, which was $3.65 \pm 0.70 \mathrm{~L} / \mathrm{min}$ vs. $4.57 \pm 1.02 \mathrm{~L} / \mathrm{min}$, respectively, $(P<0.05)$ at $72 \mathrm{~h}$ on ECMO and $3.65 \pm 0.86 \mathrm{~L} /$ min vs. $4.62 \pm 0.90 \mathrm{~L} / \mathrm{min}$, respectively, $(P<0.01)$ at $96 \mathrm{~h}$ on ECMO (Additional files 1 and 2).

\section{IPPV parameters in patients on ECMO}

In the successfully weaned group compared to the unsuccessfully weaned group, $\mathrm{FiO}_{2}$ was $46 \pm 13 \%$ vs. $74 \pm$ 
Table 2 Parameters on ECMO, IPPV parameters and physiological indicators pre and on ECMO

\begin{tabular}{|c|c|c|c|c|c|}
\hline Variable & 6 h pre-ECMO & $24 \mathrm{~h}$ on ECMO & $48 \mathrm{~h}$ on $\mathrm{ECMO}$ & $72 \mathrm{~h}$ on ECMO & $P$ value \\
\hline Blood flow (L/min) & - & $3.84 \pm 0.87$ & $4.48 \pm 0.77$ & $4.18 \pm 1.00$ & $0.023^{*}$ \\
\hline \multicolumn{6}{|l|}{ IPPV parameters } \\
\hline $\mathrm{FiO}_{2}$ & $94(55-100)$ & $50(40-80)$ & $45(40-60)$ & $46(40-50)$ & $<0.001^{*}$ \\
\hline PEEP $\left(\mathrm{cmH}_{2} \mathrm{O}\right)$ & $14 \pm 4$ & $12 \pm 5$ & $11 \pm 3$ & $11 \pm 2$ & $0.022^{*}$ \\
\hline $\mathrm{VT}(\mathrm{ml})$ & $439 \pm 61$ & $285 \pm 94$ & $317 \pm 103$ & $308 \pm 128$ & $<0.001^{*}$ \\
\hline $\mathrm{P}_{\text {plat }}\left(\mathrm{cmH}_{2} \mathrm{O}\right)$ & $29 \pm 8$ & $23 \pm 6$ & $23 \pm 5$ & $24 \pm 7$ & $0.004^{*}$ \\
\hline \multicolumn{6}{|l|}{ Physiological indicators } \\
\hline Heart Rate (/min) & $103 \pm 27$ & $90 \pm 24$ & $85 \pm 22$ & $90 \pm 25$ & $0.025^{*}$ \\
\hline MAP (mmHg) & $84 \pm 15$ & $87 \pm 15$ & $81 \pm 21$ & $94 \pm 17$ & 0.057 \\
\hline Respiratory Rate (/min) & $31 \pm 7$ & $19 \pm 6$ & $16 \pm 6$ & $16 \pm 6$ & $<0.001^{*}$ \\
\hline $\mathrm{pH}$ & $7.33 \pm 0.10$ & $7.42 \pm 0.10$ & $7.39 \pm 0.10$ & $7.43 \pm 0.10$ & $0.006^{*}$ \\
\hline $\mathrm{PaCO}_{2}(\mathrm{mmHg})$ & $52.4 \pm 16.6$ & $34.1 \pm 9.8$ & $38.3 \pm 10.5$ & $38.2 \pm 7.8$ & $<0.001^{*}$ \\
\hline $\mathrm{PaO}_{2}(\mathrm{mmHg})$ & $56.3 \pm 20.9$ & $90.0 \pm 35.9$ & $94.8 \pm 45.7$ & $104.4 \pm 57.5$ & $<0.001^{*}$ \\
\hline Lactate (mmol/L) & $2.8 \pm 1.9$ & $3.1 \pm 3.7$ & $4.0 \pm 4.8$ & $2.9 \pm 2.7$ & 0.625 \\
\hline
\end{tabular}

Note: ECMO extracorporeal membrane oxygenation, IPPV invasive positive pressure ventilation, $F_{2} \mathrm{O}_{2}$ fraction of inspiration, $P E E P$ positive end-expiratory pressure, $V T$ tidal volume, $P_{\text {plat }}$ plateau pressure, $M A P$ mean arterial pressure, $\mathrm{SpO}_{2}$ fingertip pulse oxygen saturation, $\mathrm{PaCO}$ partial pressure of arterial carbon dioxide, $\mathrm{PaO} \mathrm{O}_{2}$ partial pressure of arterial oxygen ${ }^{*} \mathrm{P}<0.05$

$25 \%$, respectively, $(P<0.01)$ at $48 \mathrm{~h}$ and $45 \pm 11 \%$ vs. $78 \pm$ $24 \%$, respectively, $(P<0.01)$ at $72 \mathrm{~h}$ on ECMO; monitored $\mathrm{P}_{\text {plat }}$ was $21 \pm 3 \mathrm{cmH}_{2} \mathrm{O}$ vs. $25 \pm 5 \mathrm{cmH}_{2} \mathrm{O}$, respectively, $(P<0.05)$ at $48 \mathrm{~h}$, and $19 \pm 4 \mathrm{cmH}_{2} \mathrm{O}$ vs. $29 \pm 6 \mathrm{cmH}_{2} \mathrm{O}$, respectively, $(\mathrm{P}<0.01)$ at $72 \mathrm{~h}$ on ECMO; and monitored VT was $246 \pm 93 \mathrm{ml}$ vs. $343 \pm 96 \mathrm{ml}$, respectively, $(P<$ $0.05)$ at $48 \mathrm{~h}$, and $236 \pm 113 \mathrm{ml}$ vs. $356 \pm 116 \mathrm{ml}$, respectively, $(P<0.05)$ at $72 \mathrm{~h}$ on ECMO; all of the differences were statistically significant (Fig. 2, Additional file 1).

\section{Improvement in circulatory and respiratory physiological indicators on ECMO}

The vital signs were improved but did not significantly differ between the two groups pre-ECMO and during ECMO support (Additional file 3). Patients who were unsuccessfully weaned from ECMO compared to patients who were successfully weaned from ECMO had severe acidosis (pH: $7.29 \pm 0.14$ vs. $7.40 \pm 0.05$, respectively, $(P<0.01)$, a higher $\mathrm{PaCO}_{2}(57.0 \pm 16.7 \mathrm{mmHg}$ vs. $43.6 \pm 13.0 \mathrm{mmHg}$, respectively, $(P<0.05)$, and a higher lactate concentration $(3.6 \pm 2.1 \mathrm{mmol} / \mathrm{L} \quad$ vs. $1.7 \pm$ $0.8 \mathrm{mmol} / \mathrm{L}, \mathrm{P}<0.05)$ pre-ECMO. $\mathrm{pH}$ and $\mathrm{PaCO}_{2}$ did not differ significantly between the two groups during ECMO support, while patients who were eventually successfully weaned from ECMO had a gradual ascending tendency of $\mathrm{PaO}_{2}$ at 48 and $72 \mathrm{~h}$ on ECMO and a sustained low level of lactate (Fig. 2, Additional file 1).

\section{Changes in anticoagulation on ECMO}

During the early stage of ECMO ( 24 and $48 \mathrm{~h}$ ), the successful weaning group showed smaller differences between the $\mathrm{ACT}_{\text {max }}$ and $\mathrm{ACT}_{\text {min }}$ than the unsuccessful weaning group, which was $48 \pm 20 \mathrm{~s}$ vs. $104 \pm 35 \mathrm{~s}$ at $24 \mathrm{~h}(P<0.05)$ and $40 \pm 25 \mathrm{~s}$ vs. $98 \pm 40 \mathrm{~s}$ at $48 \mathrm{~h}(P<0.01)$. However, this trend was not found with regard to the difference between the maximum and minimum APTT.

\section{Complications during ECMO}

There were no differences between the two groups in mechanical complications associated with ECMO, VAP and barotrauma. The successfully weaned group compared to the unsuccessfully weaned group had a lower haemorrhage rate $(28.6 \%$ vs. $77.3 \%$, respectively, $P<$ $0.01)$, lower rate of renal insufficiency $(21.4 \%$ vs. $63.6 \%$, respectively, $P<0.05)$, lower rate of liver failure $(0 \%$ vs. $40.9 \%$, respectively, $P<0.01$ ) and lower heart failure rate ( $35.7 \%$ vs. $77.3 \%$, respectively, $P<0.05$ ).

\section{Discussion}

This study was the first to systematically and comprehensively discuss as well as elaborate on the current application of the efficacy and safety of ECMO in patients with H7N9 pneumonia-related ARDS.

A few studies $[17,20,21,22]$ have shown that the mortality of pH1N1-induced ARDS was reduced to $21-61 \%$ following ECMO treatment. Presently, no studies with large samples have investigated the mortality of H7N9-induced ARDS, while the in-hospital mortality was as high as $63 \%$ in our study. Late initiation of ECMO, inappropriate IPPV settings during ECMO, and more ECMO complications might explain the relatively high mortality. Moreover, as a multicentre collaboration study, the experiences of ECMO 
Table 3 Complications During ECMO

\begin{tabular}{|c|c|c|}
\hline Complications & Our study (\%) & ECLS Registry Report (\%) $[18,19]$ \\
\hline \multicolumn{3}{|l|}{ ECMO Mechanical Complications } \\
\hline Oxygenator failure & 0.0 & 18 \\
\hline Oxygenator thrombosis & 14.3 & 12 \\
\hline Other sites thrombosis & 2.9 & 7.7 \\
\hline Hemorrhage & 45.7 & - \\
\hline Gastrointestinal hemorrhage & 28.6 & 4.6 \\
\hline Cerebral hemorrhage & 8.6 & $4-8$ \\
\hline Other site hemorrhage & 31.4 & - \\
\hline \multicolumn{3}{|l|}{ Organ Failure } \\
\hline Brain death & 8.6 & 3.8 \\
\hline Cerebral infarction & 2.9 & - \\
\hline Epilepsy & 2.9 & - \\
\hline Renal insufficiency & 48.6 & 33.5 \\
\hline Heart failure & 62.9 & 61.8 \\
\hline Arrhythmia with unstable hemodynamics & 5.7 & 18.2 \\
\hline Cardiac arrest & 11.4 & 9.8 \\
\hline Liver failure & 25.7 & - \\
\hline DIC & 8.6 & 3.8 \\
\hline Hemolysis & 2.9 & 7.1 \\
\hline Severe thrombocytopenia & 11.4 & - \\
\hline \multicolumn{3}{|l|}{ Nosocomial Infection } \\
\hline CRBSI & 28.6 & 21.2 \\
\hline Bacteremia of other sources & 5.7 & - \\
\hline VAP & 60.0 & - \\
\hline Urinary infections & 17.1 & - \\
\hline Barotrauma & 8.6 & - \\
\hline \multicolumn{3}{|l|}{ Metabolic } \\
\hline Hyperbilirubinemia & $4(11.4)$ & 7.3 \\
\hline Hyperglycemia & $17(48.6)$ & 18.2 \\
\hline
\end{tabular}

Note: DIC disseminated intravascular coagulation, CRBSI catheter related bloodstream infection, VAP ventilator associated pneumonia; severe thrombocytopenia refers to thrombocyte less than $20^{*} 10 \wedge 9 / \mathrm{L}$; hyperglycemia refers to blood glucose more than $13.3 \mathrm{mmol} / \mathrm{L}$

varied among the centres (Additional file 4), which might be another reason for the high mortality.

According to the Extracorporeal Life Support Organization (ELSO) data [23, 24], ECMO is indicated when death risk exceeds $80 \%$, i.e., when $\mathrm{PaO}_{2} / \mathrm{FiO}_{2}<$ $80 \mathrm{mmHg}$ on $\mathrm{FiO}_{2}>90 \%$ and the Murray score is $3-4$. Our patients met the indications for ECMO support. The duration of MV for more than 7 days pre-ECMO is an important prognostic factor for death [25]. For patients in the successfully weaned group, the duration of IPPV pre-ECMO was $5 \pm 1 \mathrm{~d}$; however, the duration was even longer among patients in the unsuccessfully weaned group $(6 \pm 4 \mathrm{~d})$. Moreover, rescue ventilation strategies were implemented for most patients before ECMO, which partially delayed the timing of ECMO. In comparison, ECMO was initiated at $2 \mathrm{~h}(1-5 \mathrm{~h})$ after IPPV among patients with pH1N1 in Australia and New Zealand in 2009 [5], which was significantly shorter than that in our cases. Therefore, we emphasized early implementation of ECMO in our patients.

The principle of IPPV during ECMO is the "lung rest strategy" [26]. The REVA registry study examined 123 patients with pH1N1-induced ARDS [6] and showed that the high $\mathrm{P}_{\text {plat }}\left(29 \mathrm{cmH}_{2} \mathrm{O}\right)$ on day 1 of ECMO was related to high mortality. In our study, the pre-ECMO $\mathrm{P}_{\text {plat }}$ level was high $\left(29 \pm 8 \mathrm{cmH}_{2} \mathrm{O}\right)$. High $\mathrm{P}_{\text {plat }}$ can lead to overdistension of the alveoli and cause lung volutrauma. The shear force between the overdistended and collapsed alveoli further aggregates VILI [27], which ultimately increases mortality. Although the $\mathrm{P}_{\text {plat }}$ values 


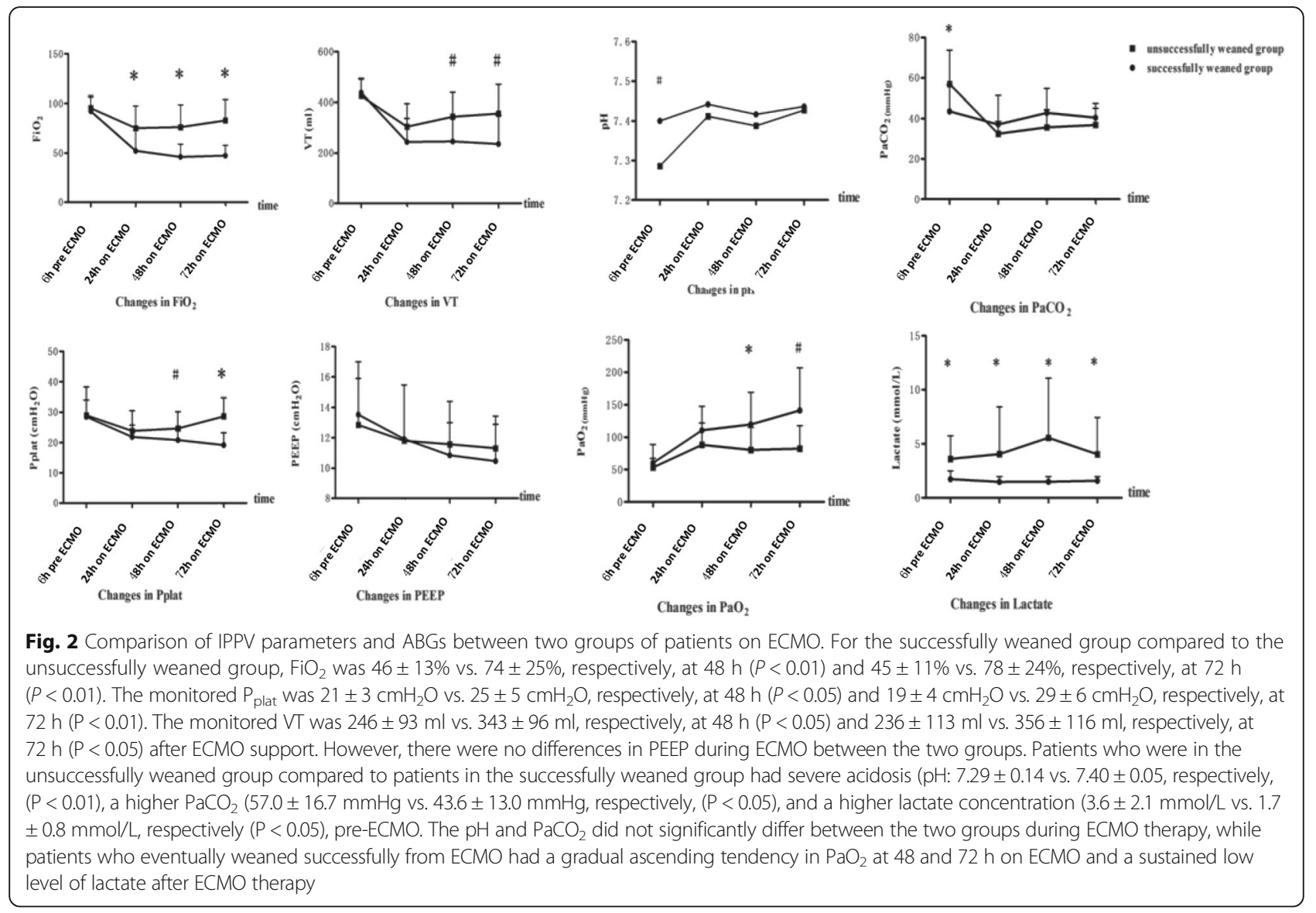

decreased to different degrees after ECMO, the $\mathrm{P}_{\text {plat }}$ of the unsuccessfully weaned group was significantly higher at 48 and $72 \mathrm{~h}$ during ECMO. The principle of low VT was similar in that we found a lower VT during ECMO in the successfully weaned group. A retrospective observational study of 168 patients with severe ARDS [28] showed that a high PEEP level within $3 \mathrm{~d}$ of being on ECMO was related to decreased mortality. Although no difference was observed in the PEEP levels between the two groups, we speculated that the down-regulation of PEEP during ECMO might have further aggravated the occurrence of collapse-induced injury, which led to atelectasis and sputum discharge obstacles. Therefore, the IPPV parameters, including high $\mathrm{P}_{\text {plat }}$ and VT levels and low PEEP settings, might have been unreasonable in our study; lung rest or the maintenance of open alveoli was not achieved.

The incidence of an ECMO oxygenator thrombus, haemorrhage, and organ failure in our study was high, which suggests that some problems existed in the anticoagulation management and organ supportive treatment of ECMO. We found that the unsuccessfully weaned group had larger fluctuations in ACT (the difference between $\mathrm{ACT}_{\max }$ and $\mathrm{ACT}_{\text {min }}$ were larger) during the early stage of anticoagulation. This effect might suggest relatively unstable anticoagulation and a higher risk of haemorrhage. Moreover, the incidence rate of VAP during ECMO was as high as 60\% and was partially attributed to the long course of H7N9 pneumonia and the prolonged duration of IPPV. Therefore, intensification of airway management was extremely necessary.

Our study had limitations. The nature of the study required the collection of data at multiple consecutive time points to evaluate the efficacy of ECMO. As a retrospective study with some missing data, we were unable to successfully collect data at $6 \mathrm{~h}$ pre-ECMO and 24,48 , and $72 \mathrm{~h}$ post-ECMO. Additionally, the number of subjects was too small to perform a multiple regression analysis to explore the risk factors for unsuccessful weaning from ECMO.

\section{Conclusions}

ECMO is effective at improving oxygenation and ventilation of patients with avian influenza A (H7N9)-induced severe ARDS. Early initiation of ECMO with appropriate IPPV settings and anticoagulation strategies are necessary to reduce complications. 


\section{Additional files}

Additional file 1: Blood flow during ECMO, changes in IPPV parameters and physiological indicators pre-ECMO and during ECMO. (DOCX 107 kb)

Additional file 2: Blood flow during ECMO between the two groups. In the successfully weaned group vs. the unsuccessfully weaned group, a significant decrease in ECMO blood flow correlated with an increase in the duration of support, which was $3.65 \pm 0.70 \mathrm{~L} / \mathrm{min}$ vs. $4.57 \pm 1.02 \mathrm{~L} /$ min, respectively, at $72 \mathrm{~h}(P<0.05)$ and $3.65 \pm 0.86 \mathrm{~L} / \mathrm{min}$ vs. $4.62 \pm 0.90 \mathrm{~L} /$ min, respectively, at $96 \mathrm{~h}(P<0.01)$. (TIFF $185 \mathrm{~kb})$

Additional file 3: Changes in vital signs pre-ECMO and during ECMO between the two groups. Vital signs were improved and did not significantly differ between the two groups during ECMO. (TIFF $204 \mathrm{~kb}$ )

Additional file 4: ECMO Cases Per Year for Each Hospital. (DOCX 60 kb)

\section{Abbreviations}

ABG: Arterial blood gas analysis; ACT: Activated coagulation time; APTT: Activated partial thromboplastin time; ARDS: Acute respiratory distress syndrome; CPAP: Continuous positive airway pressure; CRBSI: Catheter-related blood stream infection; DIC: Disseminated intravascular coagulation; ECMO: Extracorporeal membrane oxygenation; ELSO: Extracorporeal Life Support Organization; $\mathrm{FiO}_{2}$ : Fraction of inspiration; HFOV: High frequency oscillatory ventilation; IPPV: Invasive positive pressure ventilation; MAP: Mean arterial pressure; MV: Mechanical ventilation; NAI: Neuraminidase inhibitors; NPPV: Non-invasive positive pressure ventilation; $\mathrm{PaCO}_{2}$ : Partial pressure of arterial carbon dioxide; $\mathrm{PaO}_{2}$ : Partial pressure of arterial oxygen; PEEP: Positive end-expiratory pressure; PP: Prone position; Pplat: Plateau pressure; RM: Recruitment manoeuvre; SOFA: Sequential Organ Failure Assessment; $\mathrm{SpO}_{2}$ : Fingertip pulse oxygen saturation; VAP: Ventilation-associated pneumonia; VILI: Ventilation-induced lung injury; VT: Tidal volume

\section{Acknowledgements}

Not applicable.

\section{Funding}

Dr. Zhan was supported by a grant from the National Key Research and Development Programme-Major Chronic Non-Communicable Diseases' Prevention and Control (QML 2016YFC1304300). Dr. Cao was supported by a grant from the National Science Fund for Distinguished Young Scholars (grant number 81425001/H0104) and grants from the National Natural Science Foundation of China (81271840/ H1904 and 81030032/H19), and the National Program for the Prevention and Control of Human Infections by Avian-Origin H7N9 Influenza A Virus (KJYJ-2013-01-05). The funding sources had no role in the design, conduct, or reporting of the study or the decision to submit the manuscript for publication. The remaining authors have disclosed that they do not have any potential conflicts of interest.

\section{Availability of data and materials}

The datasets used and/or analysed during the current study are available from the corresponding author upon reasonable request.

\section{Authors' contributions}

All authors made substantial contributions to the conception and design of the study, data acquisition, analysis or interpretation of data, and review and approval of the final manuscript. Drs. LH, WZ, YY, WW and WL contributed equally to the article. Drs. BC and QZ assumed full responsibility for the integrity of the submission and publication and were involved in the study design. Drs. WZ, YY, WW, WL, HX, HZ, Yunfu Wu (YW), JS, LC, and LL were responsible for caring for the influenza $A(H 7 N 9)$ cases and have been involved in gathering data. Drs. LH, BC, QZ, CW, DL, and YW had full access to all of the data in the study, assume responsibility for the integrity of the data and the accuracy of the data analysis and were responsible for data verification and analysis, as well as the drafting of the manuscript.

\section{Ethics approval and consent to participate}

All patients gave written informed consent before ECMO treatment. As a highly pathogenic disease, the Chinese National Health and Family Planning Commission approved the collection of the data from the patients with H7N9 virus-induced pneumonia. The informed consent was waived to allow for exploration of the characteristics of the emerging infectious disease after rigorous contemplation and discussion by the Chinese National Health and Family Planning Commission.

\section{Consent for publication}

Not applicable.

\section{Competing interests}

The authors declare that they have no competing interests.

\section{Publisher's Note}

Springer Nature remains neutral with regard to jurisdictional claims in published maps and institutional affiliations.

\section{Author details}

${ }^{1}$ Department of Pulmonary and Critical Care Medicine, Centre for Respiratory Diseases, China-Japan Friendship Hospital, No. 2 Yinghua East Road, Chaoyang District, Beijing 100029, People's Republic of China. ${ }^{2}$ The First Affiliated Hospital of Nanchang University, Nanchang, Jiangxi Province, People's Republic of China. ${ }^{3}$ Department of Critical Care Medicine, Zhongda Hospital, Southeast University, Nanjing, Jiangsu Province, People's Republic of China. ${ }^{4}$ Department of Intensive Care Unit, Wuhan Medical Treatment Center Hospital, Wuhan, Hubei Province, People's Republic of China. ${ }^{5}$ Department of Intensive Care Unit, The First Affiliated Hospital of Wannan Medical College, Yijishan Hospital, Wuhu, Anhui Province, People's Republic of China. ${ }^{6}$ Department of Intensive Care Unit, Taizhou People's Hospital, Taizhou, Jiangsu Province, People's Republic of China. ${ }^{7}$ Department of Intensive Care Unit, Affiliated Hospital of Nantong University, Nantong, Jiangsu Province, People's Republic of China. ${ }^{8}$ Department of Intensive Care Unit, Suzhou Municipal Hospital, Suzhou, Jiangsu Province, People's Republic of China. ${ }^{9}$ Department of Infectious Diseases, Henan Provincial People's Hospital, Zhengzhou, Henan Province, People's Republic of China. ${ }^{10}$ Department of Intensive Care Unit, Dongguan People's Hospital, Dongguan, Guangdong Province, People's Republic of China. ${ }^{11}$ Department of Intensive Care Unit, The First People's Hospital of Kunshan, Kunshan, Jiangsu Province, People's Republic of China.

Received: 23 August 2017 Accepted: 10 December 2017

Published online: 08 January 2018

\section{References}

1. Gao HN, Lu HZ, Cao B, et al. Clinical findings in 111 cases of influenza A (H7N9) virus infection. N Engl J Med. 2013;368(24):2277-85.

2. Costa EL, Amato MB. The new definition for acute lung injury and acute respiratory distress syndrome: is there room for improvement? Curr Opin Crit Care. 2013;19(1):16-23.

3. Finney SJ. Extracorporeal support for patients with acute respiratory distress syndrome. Eur Respir Rev. 2014;23(133):379-89.

4. Peek GJ, Mugford M, Tiruvoipati R, et al. Efficacy and economic assessment of conventional ventilatory support versus extracorporeal membrane oxygenation for severe adult respiratory failure (CESAR): a multicentre randomised controlled trial. Lancet (London, England). 2009;374(9698):1351-63.

5. Australia, New Zealand Extracorporeal Membrane Oxygenation Influenza I, Davies A, et al. Extracorporeal membrane oxygenation for 2009 influenza A (H1N1) acute respiratory distress syndrome. JAMA. 2009;302(17):1888-95.

6. Pham T, Combes A, Roze H, et al. Extracorporeal membrane oxygenation for pandemic influenza A (H1N1)-induced acute respiratory distress syndrome: a cohort study and propensity-matched analysis. Am J Respir Crit Care Med. 2013;187(3):276-85.

7. Nie Q, Zhang DY, Wu WJ, et al. Extracorporeal membrane oxygenation for avian influenza $A$ (H7N9) patient with acute respiratory distress syndrome: a case report and short literature review. BMC Pulm Med. 2017;17(1):38.

8. Tang $X, H e ~ H$, Sun B, et al. ARDS associated with pneumonia caused by avian influenza A H7N9 virus treated with extracorporeal membrane oxygenation. Clin Respir J. 2015;9(3):380-4.

9. Wang G, Zhou Y, Gong S, et al. A pregnant woman with avian influenza A (H7N9) virus pneumonia and Ards managed with extracorporeal membrane oxygenation. Southeast Asian J Trop Med Public Health. 2015;46(3):444-8.

10. Cao B, Gao H, Zhou B, et al. Adjuvant corticosteroid treatment in adults with influenza A (H7N9) viral pneumonia. Crit Care Med. 2016;44(6):e318-28. 
11. Li Q, Zhou L, Zhou M, et al. Epidemiology of human infections with avian influenza A (H7N9) virus in China. N Engl J Med. 2014;370(6):520-32.

12. Gao R, Cao B, Hu Y, et al. Human infection with a novel avian-origin influenza A (H7N9) virus. N Engl J Med. 2013;368(20):1888-97.

13. Force ADT, Ranieri VM, Rubenfeld GD, et al. Acute respiratory distress syndrome: the Berlin definition. JAMA. 2012;307(23):2526-33.

14. Ferguson ND, Fan E, Camporota $L$, et al. The Berlin definition of ARDS: an expanded rationale, justification, and supplementary material. Intensive Care Med. 2012;38(10):1573-82.

15. Woodhead M, Blasi F, Ewig S, et al. Guidelines for the management of adult lower respiratory tract infections-summary. Clin Microbiol Infect. 2011; 17(Suppl 6):1-24.

16. Surveillance of nosocomial infections in Intensive Care Units: Hos- pital in Europe Link for Infection Control through Surveillance (HELICS) (Versión 6.1. September 2004). Available at: http://ecdc.europa.eu/en/publications/ Publications/HAI-Net-ICU-protocol-v2.2.pdf. Accessed 1 Sept 2017.

17. Papadopoulos N, Ahmad Ael S, Marinos S, et al. Extracorporeal membrane oxygenation for influenza-associated acute respiratory distress syndrome. Thorac Cardiovasc Surg. 2013;61(6):516-21.

18. Combes A, Pesenti A, Ranieri VM. Fifty years of research in ARDS. Is extracorporeal circulation the future of acute respiratory distress syndrome management? Am J Respir Crit Care Med. 2017;195(9):1161-70.

19. Paden ML1, Conrad SA, Rycus PT, Thiagarajan RR; ELSO Registry. Extracorporeal Life Support Organization Registry Report 2012. ASAIO J. 2013;59(3):202-10.

20. Wong I, Vuylsteke A. Use of extracorporeal life support to support patients with acute respiratory distress syndrome due to H1N1/2009 influenza and other respiratory infections. Perfusion. 2011;26(1):7-20.

21. Stohr F, Emmert MY, Lachat ML, et al. Extracorporeal membrane oxygenation for acute respiratory distress syndrome: is the configuration mode an important predictor for the outcome? Interact Cardiovasc Thorac Surg. 2011;12(5):676-80.

22. Freed $\mathrm{DH}$, Henzler D, White CW, et al. Extracorporeal lung support for patients who had severe respiratory failure secondary to influenza $A(H 1 N 1)$ 2009 infection in Canada. Can J Anaesth. 2010;57(3):240-7.

23. Paden ML, Conrad SA, Rycus PT, et al. Extracorporeal life support organization registry report 2012. ASAIO J. 2013:59(3):202-10.

24. Thiagarajan RR, Barbaro RP, Rycus PT, et al. Extracorporeal life support organization registry international report 2016. ASAIO J. 2017:63(1):60-7.

25. Hemmila MR, Rowe SA, Boules TN, et al. Extracorporeal life support for severe acute respiratory distress syndrome in adults. Ann Surg. 2004;240(4): 595-605. discussion -7

26. Terragni P, Faggiano C, Ranieri VM. Extracorporeal membrane oxygenation in adult patients with acute respiratory distress syndrome. Curr Opin Crit Care. 2014;20(1):86-91

27. Deans KJ, Minneci PC, Cui X, et al. Mechanical ventilation in ARDS: one size does not fit all. Crit Care Med. 2005;33(5):1141-3

28. Schmidt M, Stewart C, Bailey $M$, et al. Mechanical ventilation management during extracorporeal membrane oxygenation for acute respiratory distress syndrome: a retrospective international multicenter study. Crit Care Med. 2015;43(3):654-64.

\section{Submit your next manuscript to BioMed Central and we will help you at every step:}

- We accept pre-submission inquiries

- Our selector tool helps you to find the most relevant journal

- We provide round the clock customer support

- Convenient online submission

- Thorough peer review

- Inclusion in PubMed and all major indexing services

- Maximum visibility for your research

Submit your manuscript at www.biomedcentral.com/submit 